\title{
Ontogenetic Change in Skull Morphology and Mechanical Advantage in the Spotted Hyena (Crocuta crocuta)
}

\author{
Jaime B. Tanner, ${ }^{1,2 \star}$ Miriam L. Zelditch, ${ }^{3}$ Barbara L. Lundrigan, ${ }^{1,4}$ and Kay E. Holekamp ${ }^{1,4}$ \\ ${ }^{1}$ Department of Zoology, Michigan State University, East Lansing, Michigan 48824 \\ ${ }^{2}$ Organismic and Evolutionary Biology Program, University of Massachusetts, Amherst, Massachusetts 01003 \\ ${ }^{3}$ Museum of Paleontology, University of Michigan, Ann Arbor, Michigan 48109 \\ ${ }^{4}$ Michigan State University Museum, Michigan State University, East Lansing, Michigan 48824
}

ABSTRACT Weaning represents a challenging transition for young mammals, one particularly difficult for species coping with extreme conditions during feeding. Spotted hyenas (Crocuta crocuta) experience such extreme conditions imposed by intense feeding competition during which the ability to consume large quantities of food quickly is highly advantageous. As adult spotted hyenas have massive skulls specialized for durophagy and can feed very rapidly, young individuals are likely at a competitive disadvantage until that specialized morphology is completely developed. Here we document developmental changes in skull size, shape, and mechanical advantage of the jaws. Sampling an ontogenetic series of Crocuta skulls from individuals ranging in age from 2 months to 18 years, we use linear measurements and geometric morphometrics to test hypotheses suggesting that size, limited mechanical advantage of the jaws, and/or limited attachment sites for jaw muscles might constrain the feeding performance of juveniles. We also examine skull development in relation to key life history events, including weaning and reproductive maturity, to inquire whether ontogeny of the feeding apparatus is slower or more protracted in this species than in carnivores not specialized for durophagy. We find that, although mechanical advantage reaches maturity in hyenas at 22 months, adult skull size is not achieved until 29 months of age, and skull shape does not reach maturity until 35 months. The latter is nearly 2 years after mean weaning age, and more than 1 year after reproductive maturity. Thus, skull development in Crocuta is indeed protracted relative to that in most other carnivores. Based on the skull features that continue to change and to provide additional muscle attachment area, protracted development may be largely due to development of the massive musculature required by durophagy. These findings may ultimately shed light on the adaptive significance of the unusual "role-reversed" pattern of female dominance over males in this species. J. Morphol. 271:353-365, 2010. ๑ 2009 Wiley-Liss, Inc.

KEY WORDS: ontogeny; geometric morphometrics; growth curves; mechanical advantage; jaw morphology

\section{INTRODUCTION}

The ability to obtain and process food is essential for survival, but the functional abilities of weanling mammals may be still immature at the time of nutritional independence (Wainwright and Reilly, 1994; Monteiro et al., 1999; Herrel and Gibb, 2006). For carnivorous mammals, the functional challenges associated with weaning may be especially demanding because these animals usually feed on uncooperative and unpredictable prey, and they must often also cope with fierce competitors. Newly weaned individuals should be handicapped compared to adults due to their smaller size and inexperience, and therefore selection is expected to minimize the length of this transition period by favoring the individuals who achieve adult feeding performance maxima at the youngest ages. However, the period of morphological development often determines how early in life animals can achieve performance maxima (Carrier, 1996). Therefore, trade-offs might be expected between the time required during ontogeny to develop a feeding apparatus with adult capabilities on the one hand, and the functional capabilities of adult morphology on the other. Such trade-offs may be especially pronounced in species that possess highly specialized morphology, or face particularly challenging feeding environments.

Ecomorphologists often approach questions about performance limits by studying the functional capacities of organisms that live in extreme environments (Wainwright, 1994). Spotted hyenas

\footnotetext{
Contract grant sponsor: National Science Foundation; Contract grant numbers: IBN 0113170, IBN 0343381, IOB 0618022, IOS 0819437; Contract grant sponsor: The American Society of Mammalogists.

*Correspondence to: Jaime B. Tanner, Darwin Fellow, Organismic and Evolutionary Biology Program, University of Massachusetts, 319 Morrill S, Amherst, MA 01003-9297.

E-mail: jtanner@bio.umass.edu
}

Received 21 May 2009; Revised 15 July 2009; Accepted 12 August 2009

Published online 27 October 2009 in

Wiley InterScience (www.interscience.wiley.com)

DOI: $10.1002 /$ jmor. 10802 
(Crocuta crocuta) must simultaneously cope with two types of extreme conditions during feeding. First, adult spotted hyenas have a highly durophagous diet that involves cracking and consumption of large bones. Second, the intense feeding competition characteristic of spotted hyenas represents an extreme environment in which individuals must be able to consume large quantities of food very quickly. Because food-intake affects growth and limits reproductive success in this species (Frank et al., 1995; Hofer and East, 1996; Holekamp et al., 1996), feeding performance should have profound effects on juvenile survival. Furthermore, mortality is high among juvenile spotted hyenas, with less than half of all cubs surviving to adulthood (Frank et al., 1995; Watts, 2007). Therefore, selection should favor rapid achievement of feeding performance maxima among juvenile hyenas after weaning. However, past studies have suggested that juvenile spotted hyenas feed far more slowly than adults, even long after weaning (Biknevicius, 1996; Binder, 1998; Binder and Van Valkenburgh, 2000; Watts et al., 2009).

Adult spotted hyenas are capable of very rapid feeding and can consume over $1.3 \mathrm{~kg}$ of meat and bone per minute (Kruuk, 1972). The skull of an adult spotted hyena is highly modified to satisfy the performance demands of bone cracking. Like other bone-cracking members of the Hyaenidae, as well as extinct percrocutids and borophagine canids, adult spotted hyenas possess a number of morphological characteristics that enhance their ability to generate and sustain bite forces of great magnitude. These adaptations for durophagy include a robust and simplified dentition, large jaw adductor muscles, a pronounced sagittal crest, a vaulted forehead, wide bi-zygomatic arch breadth, increased cortical thickness of the dentary bone, and large body size (Van Valkenburgh, 2007). Furthermore, all extant bone-cracking hyaenids have an unusually long lactation period relative to other carnivores, lasting over 1 year and extending to 24 months in some cases (Kruuk, 1972; Mills, 1990; Holekamp et al., 1996; Wagner, 2006; Watts et al., 2009). This suggests that ontogenetic development of the specialized morphology of bone-cracking forms might require more time than in other species, and thus end late relative to key life history milestones.

In contrast to most other carnivores, including all other extant bone-cracking hyaenids, spotted hyenas are highly gregarious. The size of their social groups, called clans, can exceed 80 individuals (Kruuk, 1972). Each clan is structured by a linear dominance hierarchy, with social rank of each individual determining its priority of access to food. The challenges posed by weaning in spotted hyenas may thus be exacerbated not only by durophagy but also by intense feeding competition with conspecifics. It is noteworthy that, in contrast to many other gregarious carnivores, little or no provisioning of young by adults occurs among spotted hyenas (Holekamp and Smale, 1990; Mills, 1990). Therefore, without maternal assistance during feeding competition, individual feeding success after weaning in this species is likely to be directly limited by morphology. However, to date, a comprehensive analysis of ontogenetic change in the feeding apparatus has not been undertaken in any hyaenid.

Small changes in morphology can have profound effects on an animal's functional capabilities (Koehl, 1996). Feeding speed increases rapidly during the early life of the spotted hyena, but does not plateau until well after reproductive maturity (Binder and Van Valkenburgh, 2000; Tanner, 2007; Watts et al., 2009). Earlier workers proposed that feeding speed among juvenile mammals is constrained by their relatively small size, their weak chewing muscles, and poor mechanical advantage of their jaws (Biknevicius, 1996; Binder and Van Valkenburgh, 2000). Here, we collect morphological data from an ontogenetic series of skulls of knownage spotted hyenas to test hypotheses suggesting specifically that feeding speed in youngsters may be constrained by skull size, skull shape, and/or mechanical advantage of the jaw adductor muscles. We also compare patterns of morphological change in the skull before and after weaning. Finally, we consider skull development in relation to key life history events in this and other carnivore species to inquire whether the ontogeny of the feeding apparatus is slow or protracted in spotted hyenas when compared with carnivores not specialized for durophagy.

\section{MATERIALS AND METHODS Samples}

We sampled an ontogenetic series of 68 Crocuta crocuta skulls, comprised of individuals ranging in age from 2 months to 18 years, housed at the Michigan State University Museum (Fig. 1, Table 1). Most originated from a study population of spotted hyenas monitored since 1979 (Frank, 1986) in the Masai Mara National Reserve in southwestern Kenya, but the youngest specimen, a two-month-old, was obtained from a captive colony of spotted hyenas at UC Berkeley. For 37 of the specimens, including all subadults and cubs, age at death was known to \pm 7 days because these individuals were born into the study population, and their birth dates could thus be estimated based on the appearance of cubs when first observed above ground (Holekamp et al., 1996). For all other individuals, we estimated age to \pm 6 months, based on canine height and occlusal wear on the surface of the third lower premolar, as described by Van Horn et al. (2003). Mean age at weaning in the source population was 14 months, with a range of 7.5-24 months (Holekamp et al., 1996). The cause of death was known for $73 \%$ of the specimens used in the study either from direct observations or from characteristics of each carcass at the time of collection. Of all deaths of known causes, $88 \%$ were killed either by lions or by humans (usually speared by local villagers or roadkill). Only one individual was known to have died from starvation as a cub after its mother had died. Thus our sample 

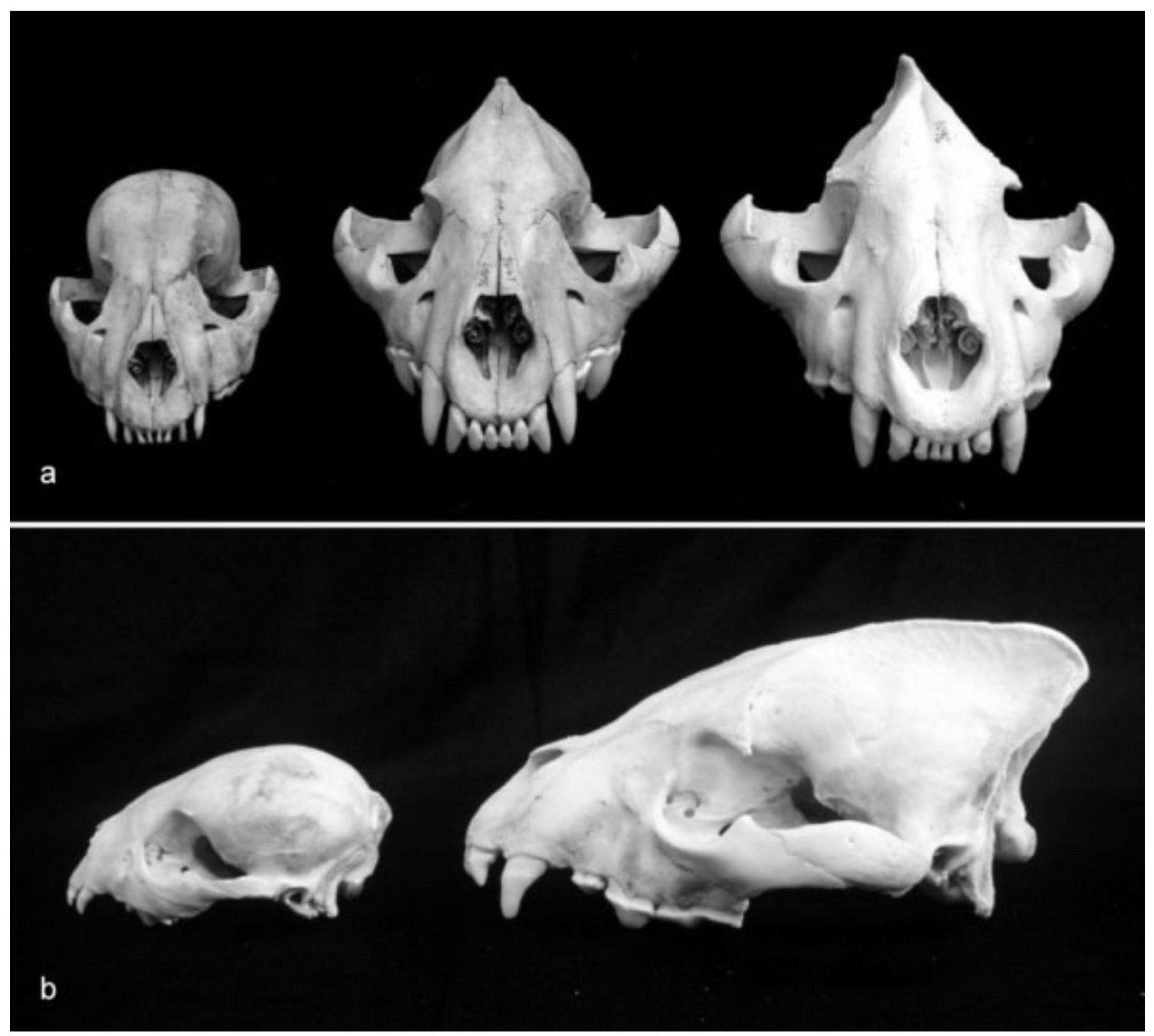

Fig. 1. Photographs of Crocuta skulls illustrating changes in size and shape throughout development (a) frontal view (from left to right) at 3 months, 20 months, and 11 years of age, and (b) lateral view at 3 months (left) and 11 years.

was not biased toward individuals that failed to thrive, as mortality was unrelated to skull form.

\section{Ontogenetic Shape Change}

To quantify changes in skull form, we used 2D landmarkbased geometric morphometrics. We analyzed three views of the skull: the ventral cranium, lateral cranium, and lateral mandible (landmarks are shown in Fig. 2 and described in Table 2). Images of the cranium in ventral view were obtained by orienting specimens with the palate parallel to the photographic plane. Images of the lateral cranium were obtained by orienting the skull with the sagittal plane parallel to the photographic plane, and those of the lateral view of the mandible were obtained by orienting the long axis of the dentary parallel to the photographic plane. Because cranial sutures are completely fused in adult hyenas (Schweikher, 1930) and because there are few landmarks on the mandible, semi-landmarks were included in our analyses of the lateral cranium and mandible (Fig. 2 and Table 2). In lateral view, semi-landmarks were positioned at the intersection of the curving perimeter of the skull and equiangular rays of a circle, defined by three landmarks $(6,11,13)$, with the rays extending from landmark 11 . These rays were calculated using MakeFan (Sheets, 2003) and the semi-landmarks along with the landmarks were digitized using tpsDig 2.10 (Rohlf, 2005). On the mandible, evenly spaced points were digitized along the outline between base landmarks ( 1 and 10, 5 and parallel to 11, 6 and 7, 8 and 9, and 9 and 12) using tpsDig 2.10. Each photograph was digitized three times on separate days by the same observer (JBT) and data for each individual were averaged. For the ventral view, bilaterally homologous coordinates were also reflected across the midline (specified by a baseline extending from landmark 1 to landmark 7, Fig. 2), and averaged, because the coordinates were not independent of each other.

Landmarks were superimposed to remove variation in scale, position, and orientation by a generalized least-squares Procrustes superimposition (Rohlf and Slice, 1990). An additional nuisance parameter must be removed when superimposing semi-landmarks because their spacing is biologically arbitrary; superimposition of semi-landmarks was done by estimating the tangent to the curve for each semi-landmark, then sliding it towards the normal of this tangent, minimizing the Procrustes distance from the mean shape. Currently, there are two main methods for sliding semi-landmarks: the first minimizes the bending-energy of the thin-plate spline (Green 1996; Bookstein 1997; Gunz et al., 2005) and the second minimizes the Procrustes distance from the mean shape (Sampson et al., 1996; Andresen et al., 2000; Bookstein et al., 2002). We used the second because the Procrustes distance is the metric underlying the general theory of shape. According to this method, the tangent to the curve at each semi-landmark is estimated. Then each semi-landmark is slid toward the normal of its respective tangent, minimizing the overall difference from the reference. Following superimposition, the coordinates of semi-landmarks can be used in any conventional shape analysis, provided that statistical tests take into account that they have only one degree of freedom. Superimposition of semi-landmarks was done in SemiLand (Sheets, 2003). 
TABLE 1. List of Michigan State University Museum skull specimens used in this study

\begin{tabular}{|c|c|c|c|}
\hline $\begin{array}{l}\text { Catalog } \\
\text { number }\end{array}$ & Age (mos) & $\begin{array}{l}\text { Catalog } \\
\text { number }\end{array}$ & Age (mos) \\
\hline 36093 & 2.00 & 36558 & 57.19 \\
\hline 36089 & 4.37 & 35857 & 61.83 \\
\hline 36088 & 4.40 & 36074 & 62.40 \\
\hline 36087 & 5.13 & 36550 & 63.13 \\
\hline 36166 & 5.47 & 36168 & 64.39 \\
\hline 36579 & 6.13 & 36553 & 65.27 \\
\hline 36086 & 7.00 & 36160 & 70.04 \\
\hline 36159 & 7.00 & 36570 & 80.87 \\
\hline 36157 & 7.20 & 36163 & 82.97 \\
\hline 36075 & 7.23 & 36079 & 83.09 \\
\hline 36155 & 7.53 & 36569 & 87.80 \\
\hline 36085 & 8.00 & 36009 & 91.22 \\
\hline 35863 & 8.57 & 35854 & 96.57 \\
\hline 35861 & 10.00 & 35853 & 96.71 \\
\hline 36010 & 11.13 & 36165 & 97.40 \\
\hline 36549 & 13.80 & 36161 & 102.50 \\
\hline 36090 & 14.37 & 35856 & 107.00 \\
\hline 36578 & 15.00 & 37464 & 107.17 \\
\hline 36167 & 15.27 & 37465 & 113.98 \\
\hline 36162 & 16.73 & 36083 & 115.20 \\
\hline 36081 & 16.87 & 36551 & 117.50 \\
\hline 36577 & 18.00 & 37466 & 119.85 \\
\hline 37463 & 20.53 & 36566 & 120.65 \\
\hline 35859 & 22.23 & 36580 & 123.65 \\
\hline 36576 & 31.60 & 36084 & 125.23 \\
\hline 36556 & 32.93 & 36008 & 128.87 \\
\hline 36156 & 38.58 & 35852 & 133.16 \\
\hline 36082 & 39.85 & 36094 & 138.36 \\
\hline 36164 & 40.35 & 36552 & 140.35 \\
\hline 35858 & 47.33 & 36011 & 143.83 \\
\hline 36581 & 47.97 & 36080 & 148.58 \\
\hline 36567 & 50.83 & 36571 & 153.00 \\
\hline 36568 & 53.47 & 36078 & 157.53 \\
\hline 35855 & 55.90 & 36077 & 199.73 \\
\hline
\end{tabular}

To analyze ontogenetic change in shape, we regressed shape on age using the log-transform of age because most shape change occurs early in ontogeny. We tested the statistical significance of the relationship between shape and age using a generalized Goodall's $F$ test (Rohlf, 2005), which measures the ratio of explained to unexplained variation in units of Procrustes distance. As well as analyzing the relationship between shape and age over the entire life span, we subdivided our sample into two life-history phases, pre- and postweaning, to determine whether changes in skull shape before and after weaning might be functionally important. For each phase, linear regressions were performed on the subgroups of skulls either older or younger than 14 months of age, generating vectors describing ontogenetic trajectories for each life history stage. We then determined whether those ontogenetic trajectories differ. When the trajectories point in the same direction, the angle between them is 0.0 degrees, so to determine whether the difference between the vectors is statistically significant, we tested the null hypothesis that the observed angle could have been produced by two independent samplings of a single ontogenetic phase. That was done by estimating the distribution of angles that could be obtained from repeated sampling of the ontogeny of a single population. The expected shape at each size is estimated from the multivariate regression equation and residuals are calculated for each individual; each specimen thus yields a multidimensional set of residuals representing its deviation from the expected shape for its size. The complete set of residuals is bootstrapped as a single unit, thus preserving the covariance structure among variables. The set of residuals (drawn at random with replacement) is added to the expected value of shape for each given size to produce a bootstrap replica of the original data set. Two ontogenetic vectors are derived from a pair of these bootstrap sets, and the angle between them is calculated. Should the observed angle between phases exceed the 95\% confidence interval of the two within-phase ranges, the difference is judged statistically significant. As sample sizes here varied for different ages, the analysis was carried out in terms of the distribution of bootstrapped data sets at comparable sample sizes.

\section{Mechanical Advantage and Muscle Size}

One method traditionally used to assess feeding ability in mammals is to model the jaw as a lever and then calculate mechanical advantage of the feeding apparatus (Radinsky, 1981; Greaves, 1983; 1985; Thomason, 1991; Smith, 1993). Using this approach, relative bite force can be inferred by estimating both the mechanical advantage of the primary

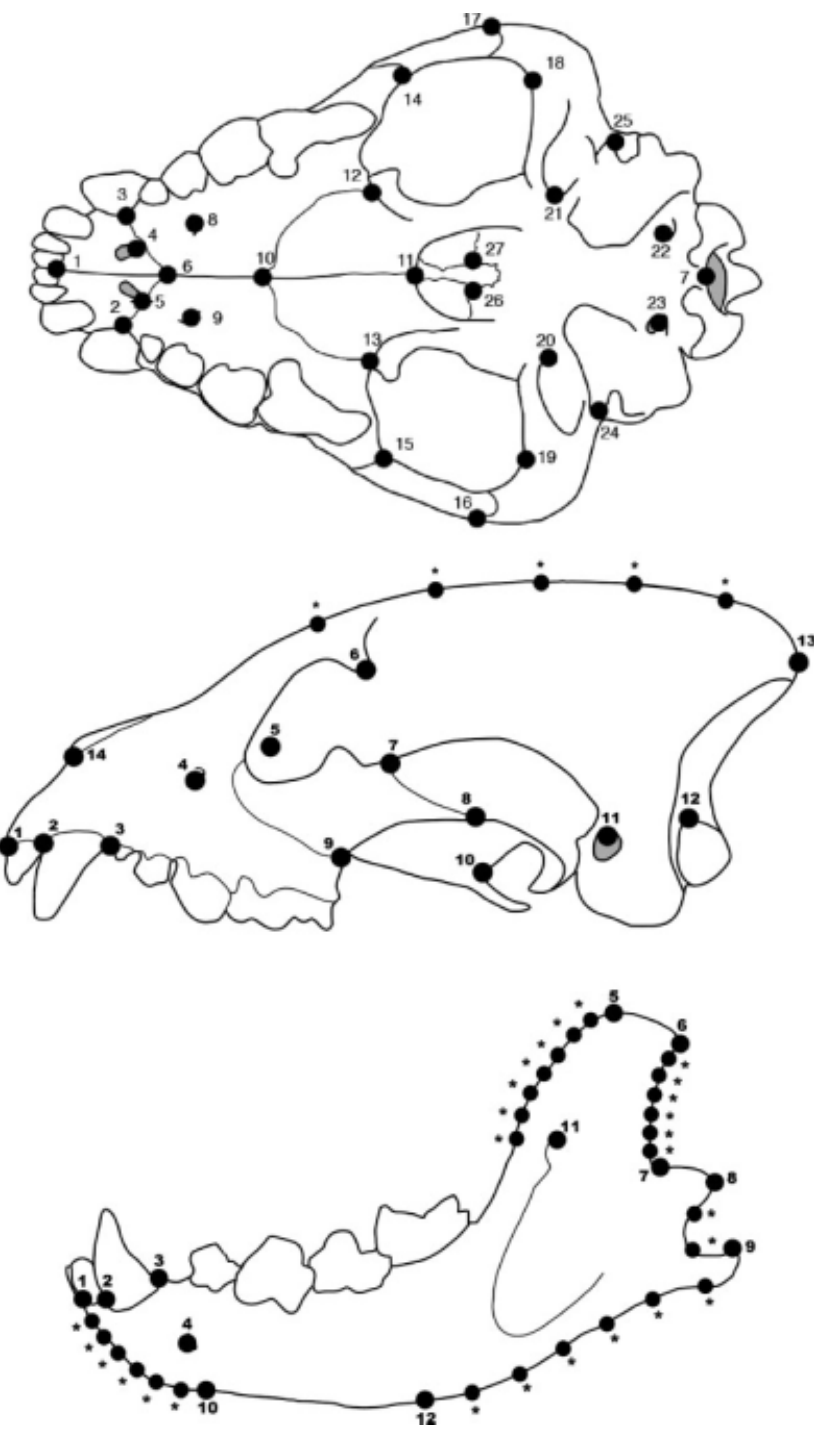

Fig. 2. Landmarks digitized in each view used in the study, (*) indicates a semi-landmark in the lateral cranium or mandible view. Bilaterally homologous landmarks in the ventral view were reflected and averaged for analyses. See Table 2 for landmark descriptions. 
TABLE 2. Description of landmarks

Ventral landmarks

1 Juncture between incisors on the premaxilla

2, 3 Premaxilla-maxilla suture where it intersects the medial edge of the canine

4, 5 Posterior-most point of the incisive foramen

6 Posterior-most premaxilla-maxilla suture on the palate

7 Anterior-most point on the foramen magnum

8, 9 Palatal foramen

10 Maxilla-palatine midline suture

11 Midline suture between the left and right palatine

12, 13 Maxilla-palatine suture on the posterior edge of the palate

14, 15 Medial edge of the maxilla-jugal suture

16, 17 Lateral edge of the jugal-squamosal suture

18, 19 Anterior lateral edge of the glenoid fossa

20, 21 Medial edge of the glenoid process

22, 23 Medial edge of the jugular foramen

24, 25 Anterior edge of the external auditory meatus

26, 27 Lateral and anterior edge of the basisphenoid

\section{Lateral landmarks}

1 Anterior point of the I3

$2 \quad$ Anterior point of the canine

3 Posterior point of the canine

4 Anterior point on the infraorbital foramen

5 Upper-most point of the lacrimal foramen

$6 \quad$ Tip of the post-orbital process

7 Upper edge of the jugal-squamosal suture

8 Ventral edge of the jugal-squamosal suture

9 Posterior edge of the premaxilla-jugal suture

10 Poster-most point of the pterygoid

11 Upper-most point on the external auditory meatus

12 Upper-most point on the occipital condyle

13 Posterior point on the nuchal crest

14 Anterior-most point on the nasal-premaxilla suture

15-19 Semi-landmark (*)

\section{Mandible landmarks}

1 Anterior point on I4

$2 \quad$ Anterior point on the canine

3 Posterior edge of the canine

4 Upper edge of the mental foramen

5 Dorsal apex of the curve on the coronoid process

$6 \quad$ Posterior edge of the coronoid process

7 Anterior edge of the mandibular condyle

8 Posterior edge of the mandibular condyle

9 Dorsal tip of the articular process

10 Posterior edge of the mandibular symphysis

11 Dorsal edge of the masseteric fossa

12 Ventral apex of the curve of the dentary

13-39 Semi-landmark (*)

*Indicated as $(*)$ in Figure 2.

masticatory muscles (the temporalis and masseter) and the size of those muscles (Radinsky, 1981; Hildebrand, 1984; Binder, 1998). Adductor muscle size is traditionally estimated by the maximal width across the zygomatic arches; the in-lever arm length is measured as the distance separating muscle insertion points and the jaw joint, and the out-lever (moment arm of resistance) is measured by the distance from the jaw joint to the bite point on the mandible (Radinsky, 1981; Gittleman and Van Valkenburgh, 1997; Binder, 1998). Over ontogeny, as the lengths of temporalis and masseteric lever arms increase relative to the length of the resistance arm, mechanical advantage increases (Hurov et al., 1988; Gittleman and Van Valkenburgh, 1997).

Following Radinsky (1981), mechanical advantage was calculated here as the in-lever divided by the out-lever, with the in-lever of the temporalis measured as the distance from the dorsal tip of the coronoid process to the mandibular condyle, and the in-lever of the masseter as the distance from the mandibular condyle to the middle of the ventral masseteric depression. The out-levers for both the temporalis and masseter were measured as the distance from the mandibular condyle to the bite point. The third lower premolar was used as the bite point in this study because that is the main tooth used for bone cracking in this species (Van Valkenburgh, 1988; Werdelin, 1989). Zygomatic arch breadth at the widest point on the skull was used to estimate jaw adductor size.

\section{Age at Maturity}

To determine the age at which skull size, shape, mechanical advantage, and zygomatic arch breadth reach maturity, we used nonlinear growth models. Several models were fitted to the data and assessed for their relative goodness-of-fit using the Aikaike Information Criterion (AIC). For all the measures obtained here (size, shape, mechanical advantage, and zygomatic arch breadth), the model having the highest AIC weight was the monomolecular model (following Gaillard et al., 1997):

$$
x(t)=A\left\{1-\exp ^{K\left(t_{0}-t\right)}\right\}
$$

where $x(t)$ is the measurement of interest at time $t, A$ is the asymptotic adult value, $K$ is the rate of approach to adult value, and $t_{0}$ is the age at which growth begins (Gaillard et al., 1997; Zelditch et al., 2003). We report age at maturity as the estimated age at which the variable reaches $95 \%$ of its asymptotic value. Data for individuals above the $95 \%$ breakpoint were subsequently regressed on age a second time to ensure that age had no further significant impact on the measurement of interest. Evaluation of growth models and estimation of parameters were done using GrowChoice (Sheets, 2003).
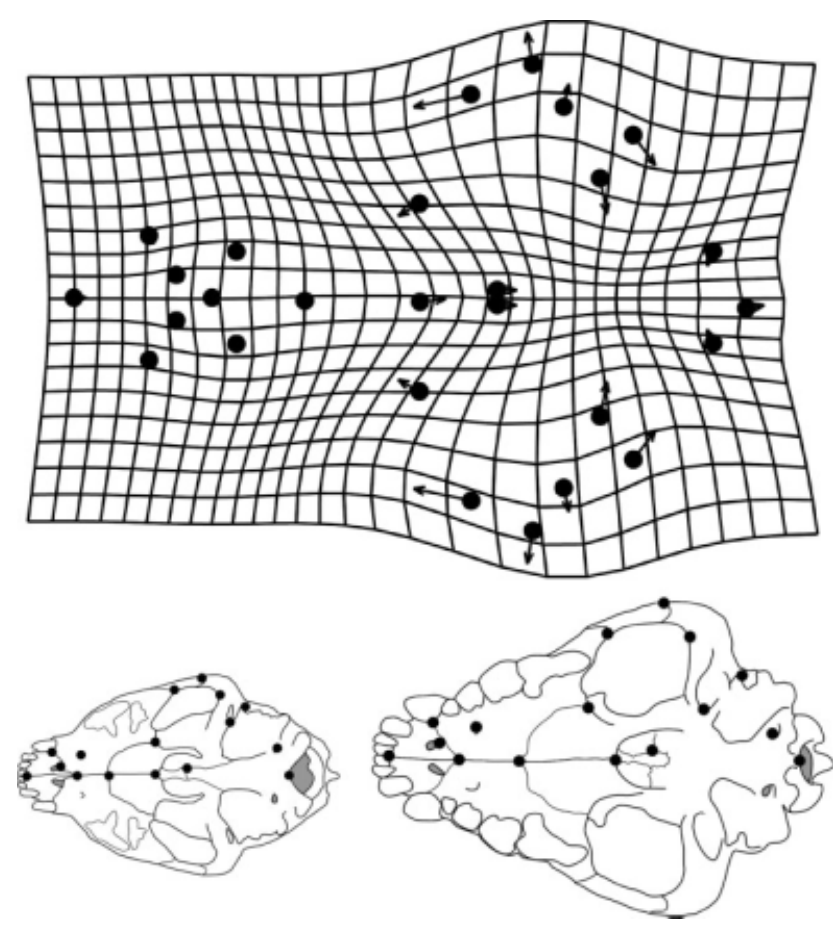

Fig. 3. Deformation grid showing ontogenetic changes from a linear regression of shape on $\log ($ age $)$ in the ventral view. The landmarks have been back reflected for ease of interpretation. Vectors show the direction and magnitude of change from the youngest to the oldest specimens after centroid size is scaled to the same size for each specimen. 

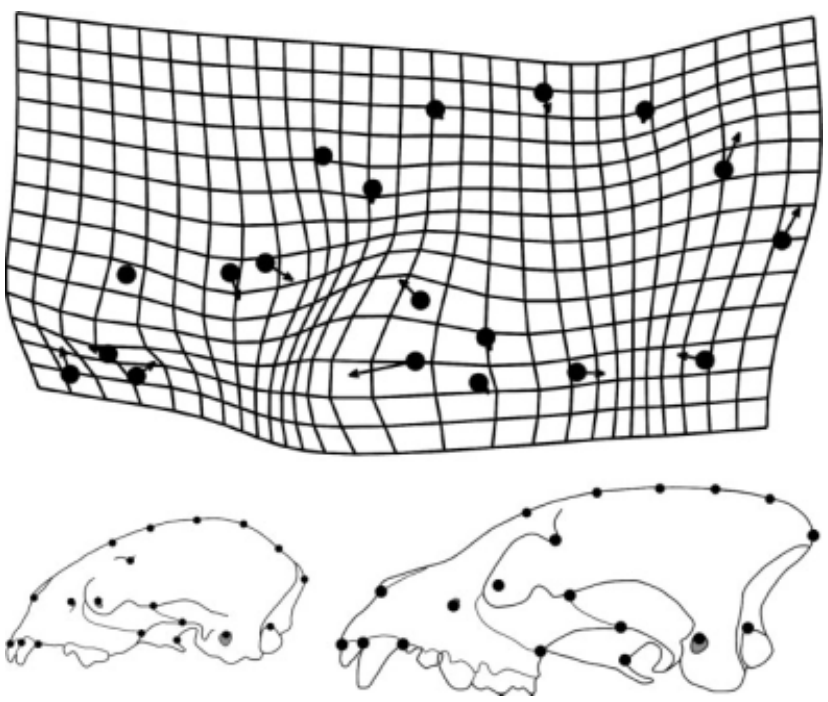

Fig. 4. Deformation grid showing ontogenetic changes from a linear regression of shape on log(age) in the lateral view. Vectors show the direction and magnitude of change from the youngest to the oldest specimens after centroid size is scaled to the same size for each specimen.

As a measure of skull size, we used centroid size, the square root of the summed squared distances from each landmark to the geometric center of the object (Bookstein, 1996; Zelditch et al., 2004). As a measure of the maturity of skull shape, we used the Procrustes distance between a specimen and the average for the youngest age class (Zelditch et al., 2003); this distance is approximately the square root of the summed square distances between homologous landmarks. We used this procedure to quantify the rate of shape maturation because more conventional methods require that species (or ontogenetic phases) have the identical trajectory for shape (e.g., Alberch et al., 1979) or else subdivide the inherently multidimensional data of shape into a collection of one-dimensional parameters that are analyzed one at a time (McKinney and McNamara, 1991). Our approach is based upon a suggestion made by Gould (1977), namely to measure the rate of change in shape by the distance traveled along a species-specific trajectory of shape. Although a large Procrustes distance between an individual and the average juvenile shape could mean that the individual is oddly shaped rather than mature, there were no major outliers in our sample.

\section{RESULTS}

\section{Change in Shape throughout Ontogeny}

Statistically significant and visually dramatic ontogenetic changes in ventral skull shape occur between 2 months and 18 years of age (Goodall's $F_{28,1764}=41.23, P<0.01$, Fig. 3). Ontogenetic change in ventral shape is dominated by a relative increase in bi-zygomatic arch breadth and lengthening of the zygomatic arches along the anteroposterior axis. Ontogenetic change in lateral shape is also statistically significant (Goodall's $F_{34,2142}=$ $33.042, P<0.01$ ). This view (see Fig. 4) similarly captures the relative lengthening of the zygomatic arches along the anteroposterior axis. In addition, the cranial profile appears to flatten owing to the posterodorsal expansion of nuchal and occipital crests. Ontogenetic change in the mandible is also statistically significant (Goodall's $F_{74,4440}=30.656$, $P<0.01$ ); the dominant features here are the relative expansion of the angular process and a marked anterodorsal reorientation of the coronoid process, resulting in a more vertical orientation of this process in adults than in juveniles (see Fig. 5).

The trajectories of pre- and post-weaning ontogenies of cranial shape differ significantly from one another for both ventral and lateral views; the angle between pre- and post-weaning phases $\left(89.1^{\circ}\right.$ for ventral; $118.5^{\circ}$ for lateral) is much larger than the angles within each phase $\left(49.2^{\circ}, 56.9^{\circ}\right.$ for ventral; $24.5^{\circ}, 37.8^{\circ}$ for lateral). Before weaning, change in ventral view is characterized primarily by relative lengthening of the zygomatic arches and palate along the anteroposterior axis and narrowing of the basicranium (Goodall's $F_{28,364}=$ 5.76, $P<0.01$, Fig. 6a). After weaning, the zygomatic arches continue to lengthen along the anteroposterior axis; there is a marked increase in relative bi-zygomatic arch breadth, as well as a slight relative lengthening of the medial palate (Goodall's $F_{28,1428}=9.44, P<0.01$, Fig. $\left.6 \mathrm{~b}\right)$. In lateral view, over the pre-weaning phase, the braincase becomes much less bulbous, and there is an increase in the length of the rostrum relative to other skull dimensions (Goodall's $F_{34,442}=16.98$, $P<0.01$, Fig. 7a). After weaning, the dominant changes are the relative lengthening of the zygomatic arches along the anteroposterior axis and development of the sagittal and nuchal crests (Goodall's $F_{34,1734}=15.03, P<0.01$, Fig. $7 b$ ).

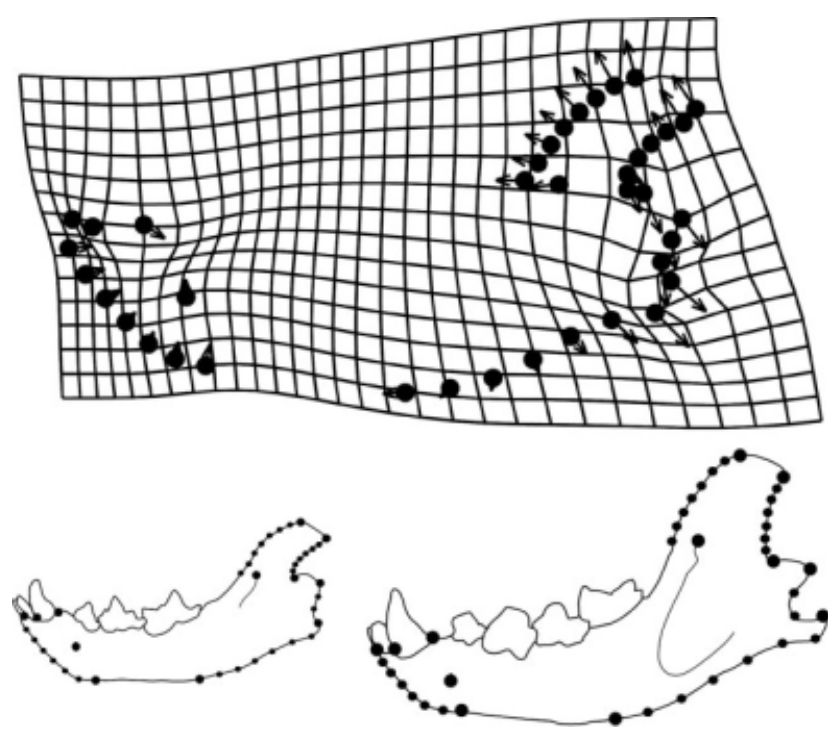

Fig. 5. Deformation grid showing ontogenetic changes from a linear regression of shape on log(age) in the lateral view of the mandible. Vectors show the direction and magnitude of change from the youngest to the oldest specimens after centroid size is scaled to the same size for each specimen. 

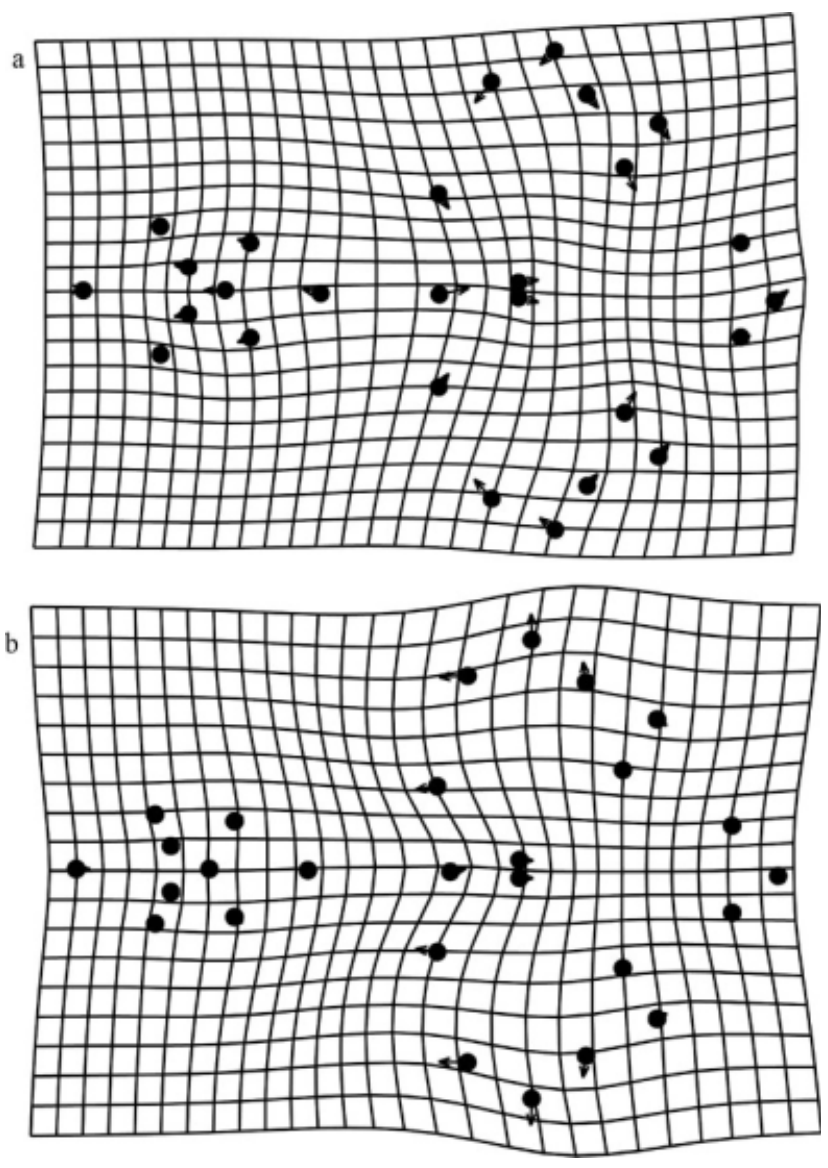

Fig. 6. Deformation grids showing ontogenetic change from a linear regression of shape on $\log$ (age) in the ventral view; (a) from 2 months until weaning (14 months), and (b) from weaning until 18 years.

\section{Age at Maturity}

Skull size reaches $95 \%$ of its asymptotic value around the time of reproductive maturity or shortly thereafter in the ventral, lateral, and mandible views (26, 29, and 24 months, respectively; Fig. 8). For skull shape, change is initially rapid in all three views, but the rate diminishes more gradually in ventral than in the other views (see Fig. 9). Lateral view shape reaches $95 \%$ of its asymptotic value by 18 months, the mandible by 23 months, but the ventral skull not until 35 months of age.

\section{Mechanical Advantage and Muscle Size}

Mechanical advantage of the temporalis (Fig. 10a) increases rapidly before leveling off at 22 months of age, shortly before reproductive maturity. In contrast, there is no clear pattern of ontogenetic change in mechanical advantage of the masseter (Fig. 10b). Change in zygomatic arch breadth, reflecting the size of the jaw musculature, continues to increase until 33 months of age (Fig. 10c).

\section{Skull Maturity in Relation to Life History Milestones}

Data documenting age at full skull maturity are available for only six carnivore species other than the spotted hyena (Table 3). Most of these studies used traditional linear morphometric measurements rather than geometric morphometrics. They suggest considerable variation in the relative timing of reproductive maturity and skull maturity. Of the seven species, the spotted hyena, male polar bear (sometimes), and brown bear exhibit the most protracted skull development, with adult morphology not achieved until well after reproductive maturity.

\section{DISCUSSION \\ Patterns of Skull Development}

Skull size, skull shape, and mechanical advantage of the temporalis muscles change dramatically as spotted hyenas mature. A summary timeline of these changes, shown in relation to both chronological age and life history milestones, is presented in Figure 11. Although age at maturity for skull size and shape varies among the three views (ventral, lateral, and mandible), we indicate for each only the age at maturity for the view that matures latest. It is notable that all the skull parameters analyzed here reach maturity well after weaning.
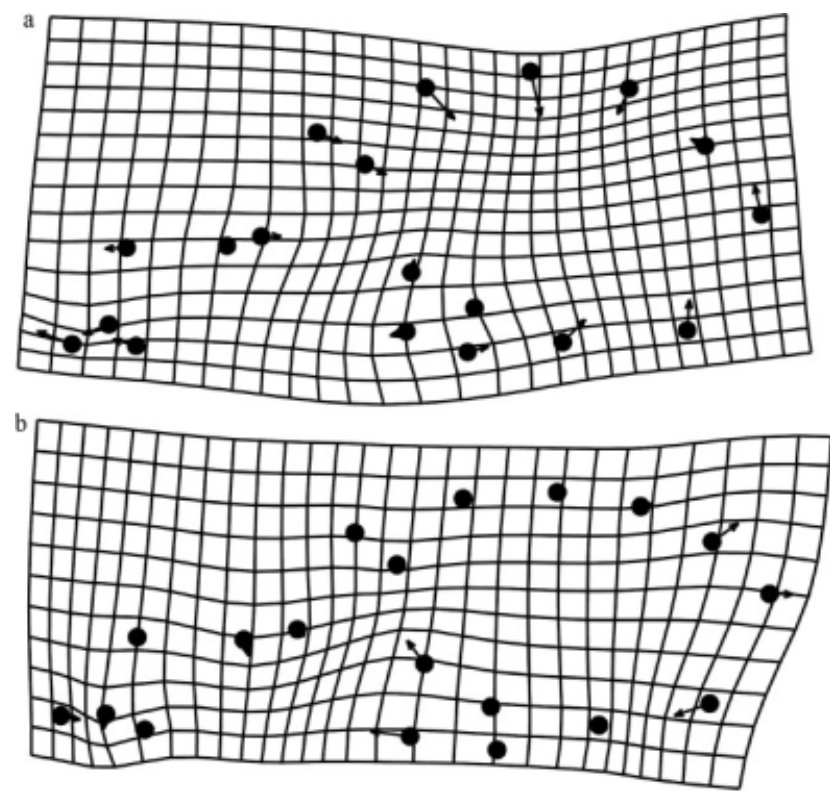

Fig. 7. Deformation grids showing ontogenetic change from a linear regression of shape on $\log ($ age $)$ in the lateral view; (a) from 2 months until weaning (14 months), and (b) from weaning until 18 years. 

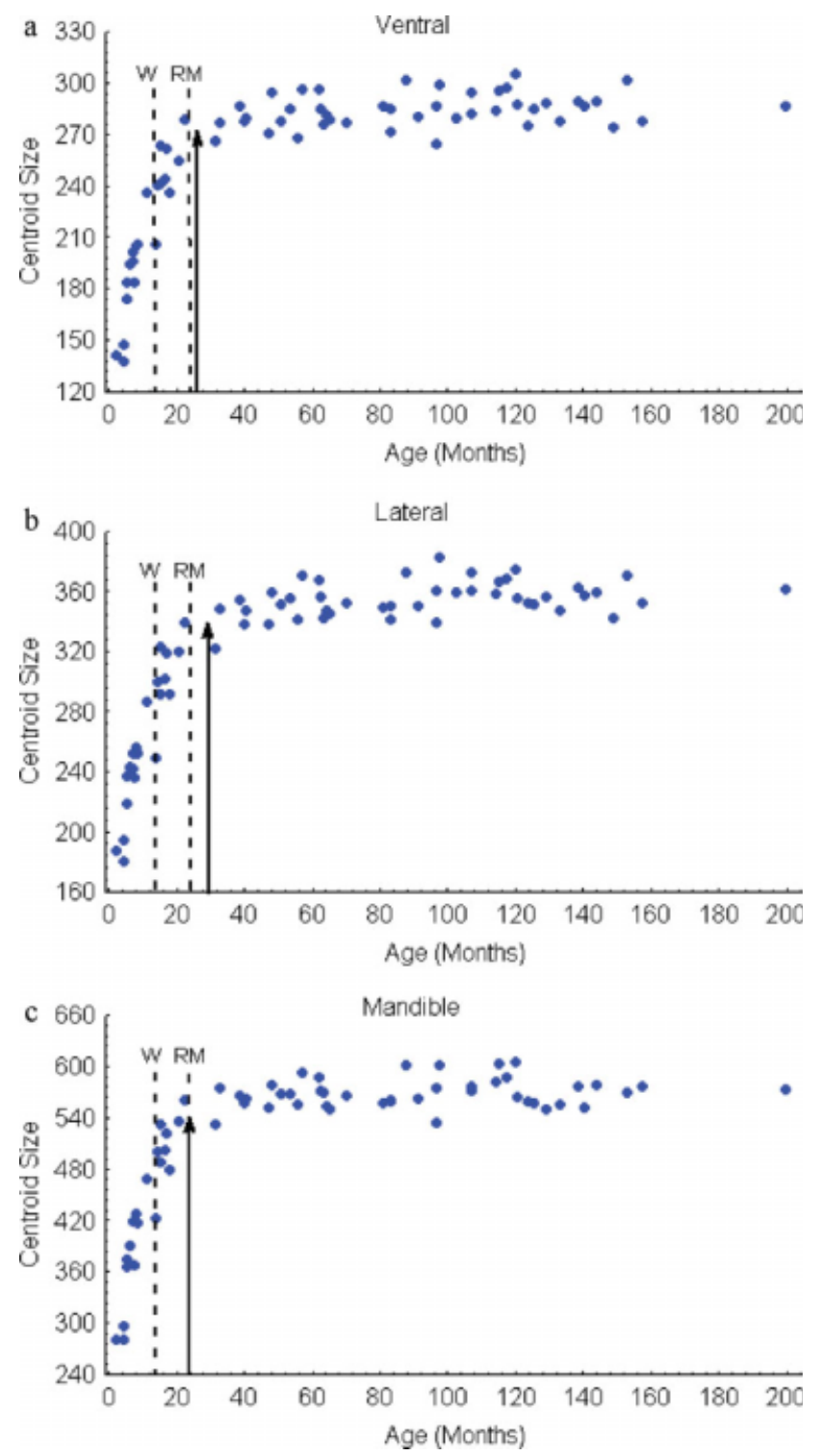

Fig. 8. Growth curves for skull centroid size for the (a) ventral, (b) lateral cranium, and (c) lateral mandible view. Arrows indicate $95 \%$ of asymptotic values based on the monomolecular equation. Dotted lines indicate the average ages at weaning (W) and reproductive maturity $(\mathrm{RM})$. [Color figure can be viewed in the online issue, which is available at www.interscience. wiley.com.]

Furthermore, although rates of change in centroid size, Procrustes distance, and linear skull measurements all slow after puberty, most continue to change even after hyenas are reproductively mature. Not surprisingly, we found that mandible size, mandible shape, and mechanical advantage of the temporalis muscle reach maturity in close temporal association, at 24,23 , and 22 months of age, respectively; this is later than maturity of cranial shape in lateral view, which reaches $95 \%$ of its asymptotic value by 18 months. The relatively early termination of shape change in the lateral view is surprising given that changes in lateral shape after 18 months are clearly apparent on visual inspection, particularly in the region of the sagittal crest. This apparent contradiction may be due to distortion caused by projecting a 3D image onto a 2D photographic plane. In ventral view, cranial shape does not reach $95 \%$ of the asymptotic value until 35 months, and the features that dominate ontogenetic change are both associated with masticatory musculature: bi-zygomatic arch breadth and length of the zygomatic arches along the anteroposterior axis.
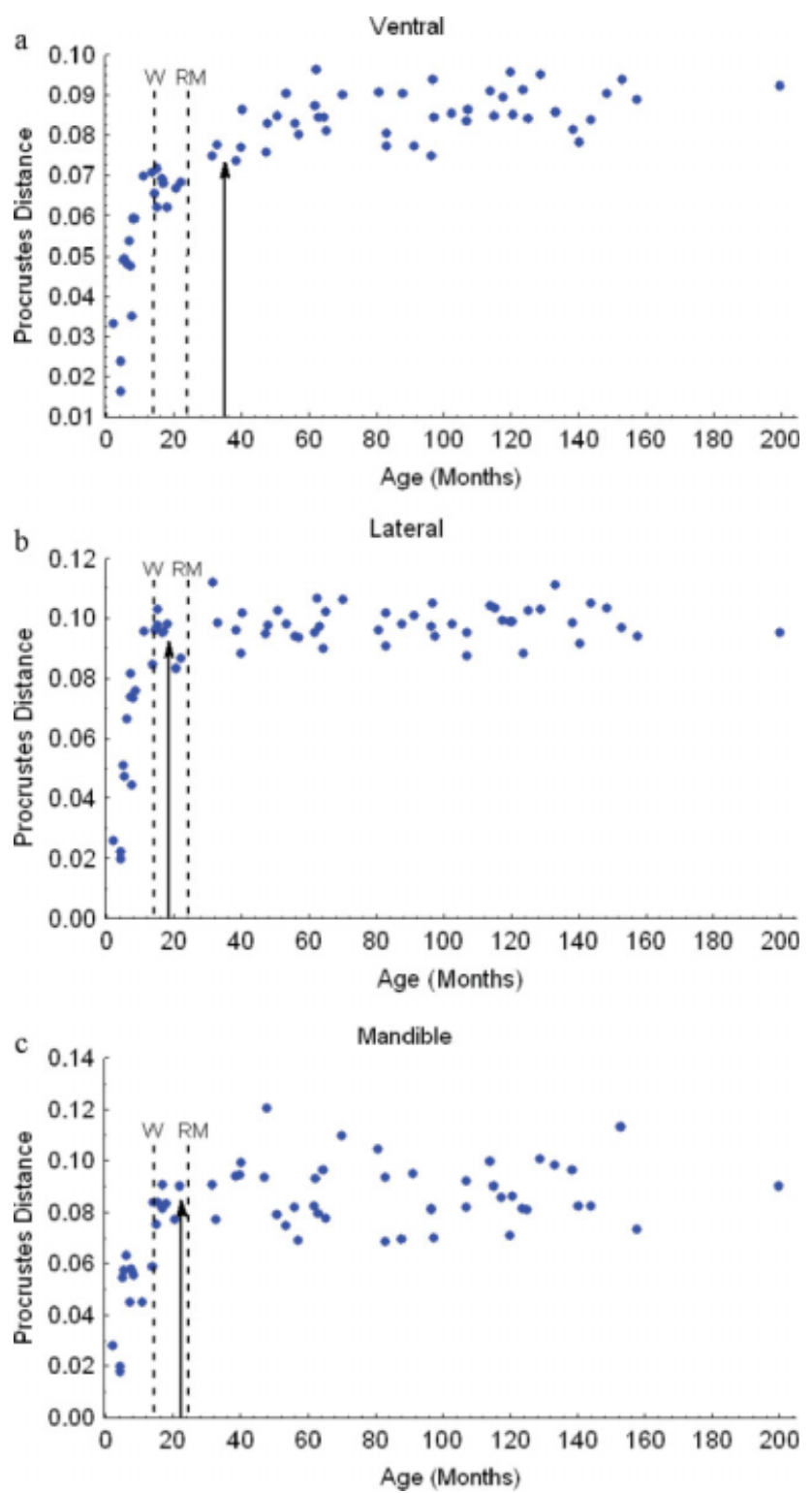

Fig. 9. Growth curves for skull shape (procrustes distance) for the (a) ventral, (b) lateral cranium, and (c) lateral mandible view. Other symbols are as in Fig. 8. [Color figure can be viewed in the online issue, which is available at www.interscience. wiley.com.] 

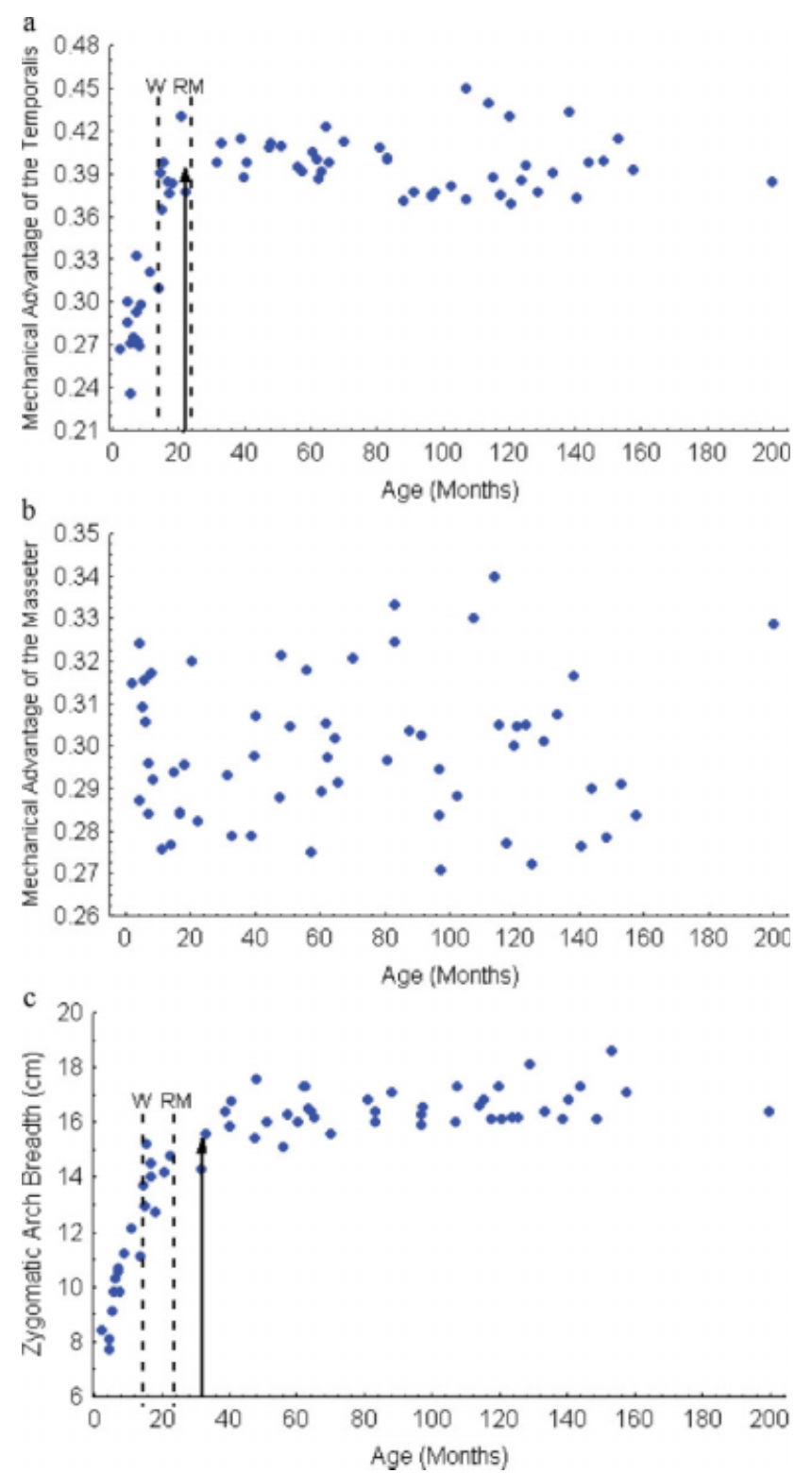

Fig. 10. Growth curves for (a) mechanical advantage of the temporalis, (b) mechanical advantage of the masseter, and (c) zygomatic arch breadth. Other symbols are as in Fig. 8. [Color figure can be viewed in the online issue, which is available at www.interscience.wiley.com.]

Even the skull features that mature earliest do so well after weaning. On average, spotted hyenas in our free-living study population are weaned at 14 months of age (Holekamp et al., 1996), so like other bone-cracking hyaenids, these animals are weaned quite late relative to other carnivores (Gittleman, 1989; Watts et al., 2009). Despite the long lactation period, newly weaned spotted hyenas are still far from adult size and shape (Figs. 8 and 9). Furthermore, we document distinctly different patterns of change in skull shape before versus after weaning (Figs. 6 and 7).
Before cubs become nutritionally independent of their mothers, the most pronounced shape changes involve relative lengthening of the rostrum and reshaping of the cranium to produce a less bulbous profile. The lengthening of the rostrum and palate likely reflect tooth eruption and the acquisition of adult dentition that occurs before weaning. After weaning, shape change is most pronounced in regions of the skull associated with adductor muscle mass and area of insertion. Specifically, the zygomatic arches expand, and both the sagittal and nuchal crests develop.

The primary parameter commonly measured for biomechanical analyses of the jaw is mechanical advantage, which increases when moment arm length increases relative to that of the out-lever. During ontogeny, both in-levers and out-levers increase with increasing overall size, but if the length of the in-lever increases faster than that of the out-lever, mechanical advantage of the associated jaw musculature also increases. Our data show that mechanical advantage of the masseter does not increase over the course of spotted hyena ontogeny, indicating isometric growth of the two lever arms (Fig. 10b). In contrast, mechanical advantage of the temporalis increases sharply over ontogeny, with adult form not reached until $\sim 22$ months of age. The temporalis is by far the larger of the two main adductor muscles in Crocuta as it is in other carnivores.

\section{Mediation of Feeding Performance}

Previous studies have assessed ontogenetic variation in bite force among captive spotted hyenas and other mammals (Binder and Van Valkenburgh, 2000; Thompson et al., 2003), and bite force measures are certainly ecologically relevant for bone-cracking animals like spotted hyenas. Although the lever ratios for the temporalis in the hyena's jaw cease changing by 22 months of age, we would expect bite force to increase for nearly another year, coincident with increasing zygomatic arch breadth and associated muscle mass. Bite force, however, is only one of a suite of performance measures associated with feeding. Gape and feeding speed also influence carnivore feeding performance. Absolute jaw length dictates gape, which determines the size of bones that individuals can effectively crack open (Binder, 1998; Binder and Van Valkenburgh, 2000). The increase in relative length of the rostrum and mandible seen here during preweaning hyena development should enhance this aspect of feeding performance. Furthermore, an increase in jaw length reflects the replacement of dentition, which also has implications for both bite force (Binder, 1998) and feeding speed (Tanner, 2007). 
TABLE 3. A comparison of age at skull maturity relative to age at reproductive maturity for a number of carnivoran species

\begin{tabular}{|c|c|c|c|c|c|}
\hline Species & $\begin{array}{l}\text { Age at } \\
\text { weaning } \\
\text { (months) }\end{array}$ & $\begin{array}{l}\text { Age at } \\
\text { reproductive } \\
\text { maturity } \\
\text { (years) }\end{array}$ & $\begin{array}{l}\text { Age at } \\
\text { first } \\
\text { breeding } \\
\text { (years) }\end{array}$ & $\begin{array}{l}\text { Age at } \\
\text { skull } \\
\text { maturity } \\
\text { (years) }\end{array}$ & Sources \\
\hline $\begin{array}{l}\text { Spotted hyenas } \\
\text { (Crocuta crocuta) }\end{array}$ & $8-24$ & 2 & 2 & 3 & Present study (Watts, 2007) \\
\hline $\begin{array}{l}\text { Spotted seal } \\
\quad(\text { Phoca largha })\end{array}$ & $0.5-1$ & $4-5$ & $?$ & 5 & $\begin{array}{l}\text { (Atkinson, 1997) (Mizuno and } \\
\text { Ohtaishi, 2002) }\end{array}$ \\
\hline $\begin{array}{l}\text { Sea otter } \\
\quad \text { (Enhydra lutris) }\end{array}$ & $6-8$ & $\begin{array}{l}+3-5 \\
+5-7\end{array}$ & $3-5$ & 2 & $\begin{array}{l}\text { (Krkosek et al, 2007) } \\
\text { (Tinker et al., 2006) } \\
\text { (Hattori et al., 2003) }\end{array}$ \\
\hline $\begin{array}{l}\text { Polar bear } \\
\quad \text { (Ursus maritimus) }\end{array}$ & $16-28$ & 5 & 5 & $\begin{array}{c}+5 \\
+3-10\end{array}$ & $\begin{array}{l}\text { (Bechshøft et al., 2008) } \\
\quad \text { (Derocher and Stirling, 1998) }\end{array}$ \\
\hline $\begin{array}{l}\text { Brown bear } \\
\quad \text { (Ursus arctos) }\end{array}$ & $18-30$ & $\begin{array}{l}+2-5 \\
+3-4\end{array}$ & 4 & $10+$ & $\begin{array}{l}\text { (Mano and Tsubota, 2002) } \\
\text { (Zedrosser et al., 2007) } \\
\text { (Ohdachi et al., 1992) }\end{array}$ \\
\hline $\begin{array}{l}\text { Coyote } \\
\quad \text { (Canis latrans) }\end{array}$ & $1.2-1.6$ & 0.8 & $0.8-1.9$ & 0.42 & $\begin{array}{l}\text { (Bekoff and Gese, 2003) } \\
\text { (LaCroix et al, } \\
\text { unpublished data) }\end{array}$ \\
\hline $\begin{array}{l}\text { Black-backed Jackal } \\
\text { (Canis mesomelas) }\end{array}$ & $1.8-2.3$ & 0.9 & 2 & $0.3-0.5$ & $\begin{array}{l}\text { (Walton and Joly, 2003) } \\
\quad \text { (Lombard, 1971) }\end{array}$ \\
\hline
\end{tabular}

All studies except for this study and that of LaCroix et al. used traditional linear morphometric measurements.

Feeding speed is expected to be a critical determinant of performance in spotted hyenas, because these animals compete intensively with conspecifics over kills. We recently tested feeding speed in known-age individuals by timing consumption of a standardized soft food object, and found that wild spotted hyenas do not achieve adult performance levels until 34 months of age (Watts et al., 2009). This is only 1 month before skull shape reaches maturity, but long after skull size and mechanical advantage of the temporalis muscle reach adult values (see Fig. 11). This difference in timing between functional maturity and the maturity of skull size suggests that skull size cannot account for low feeding speeds after 29 months of age. Similarly, mechanical advantage of the temporalis muscles, which is known to affect feeding performance in other mammals (e.g., Dessem and Druzinsky, 1992; Thompson et al., 2003), can only potentially account for low feeding speeds among hyenas younger than 22 months old.

The only hypothesis consistent with our data is that juvenile feeding speed is largely constrained after puberty by aspects of skull form that limit the mass of adductor muscles. With increasing muscle mass and changes in muscle architecture, both bite force and feeding speed should increase even with mechanical advantage held constant. Changes in hyena skull morphology after weaning are dominated by an increase in the size of the space through which the masseter and temporalis muscles pass and an expansion of attachment areas for those muscles. This is apparent from the absolute increase in zygomatic arch breadth (Fig. 10c), which presumably corresponds to increasing size of the jaw adductor muscles. It is more thoroughly defined by the geometric morphometric analyses (Figs. 6 and 7), which indicate not only an increase in zygomatic breadth after weaning but also a relative anteroposterior lengthening of the zygomatic arches (see Fig. 3), and development of the sagittal and nuchal crests (see Fig. 4), all of which should provide more muscle attachment area for the adductor muscles. Both the tem-

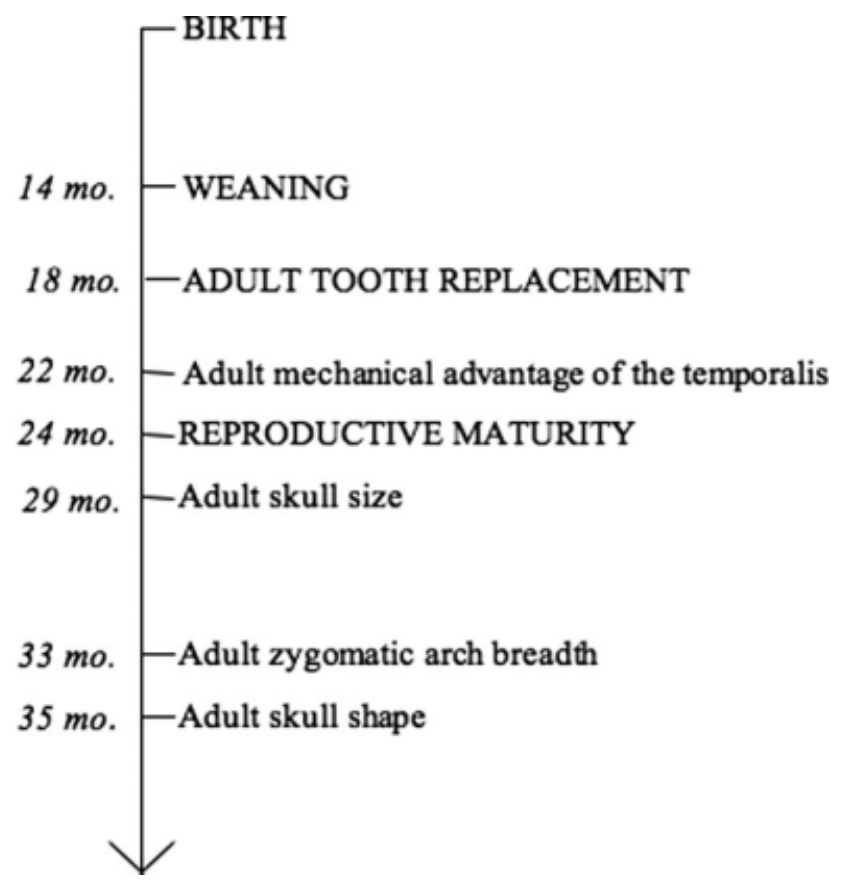

Fig. 11. A timeline illustrating the ages at maturity for morphological measures in relation to major life history events (in capital letters). 
poralis and masseter are importantly involved in jaw closure and bite force generation in all mammals, but the unusually large size of the temporalis in Crocuta (Tanner et al., 2008) suggests that this muscle plays a disproportionately large role in feeding among bone-cracking hyaenids.

\section{Evolutionary Implications of Protracted Skull Development}

Feeding performance is expected to improve during ontogeny as juvenile mammals shift from a relatively easy diet comprised mainly of milk, to one that is more challenging after weaning. Weaned juvenile hyenas compete for the same food resources as those consumed by adults. However, when competing with adults at ungulate kills, where the ability to feed rapidly confers huge energetic benefits, juveniles are clearly severely disadvantaged. The developmental transition from a juvenile skull with a feeding apparatus ill-suited for a durophagous diet, to an adult skull highly specialized for durophagy, continues until 35 months of age, which is nearly 2 years after nutritional independence from the mother (see Fig. 11). This is not only long after weaning but also long after spotted hyenas reach reproductive maturity at 24 months (see Fig. 11). The longest lifespan we have ever documented among wild spotted hyenas is 18 years and the mean expected lifespan for females alive at puberty is 12 years (Watts, 2007). Thus, 15-25\% of the lifespan may pass in this species before the feeding apparatus is fully mature. Postcranial measurements from this population of spotted hyenas reach maturity before sexual maturity at an average of 22 months of age (Swanson et al., unpublished data). Thus protracted development of the skull relative to that of the postcranial anatomy further suggests that there are selective pressures on the specialized skulls of these animals. There appears to be a trade-off between selection on juveniles to achieve mature feeding capabilities as early as possible and the relatively long period of time necessary to develop the specializations of the skull required to crack open and consume bones of large diameter. Unfortunately, comparable data on skull maturation are available for very few carnivore species. Those data suggest that protracted development of the skull occurs not only in spotted hyenas but also in some bears (Table 3).

Spotted hyenas are unique among carnivores, and highly unusual among mammals, in that they exhibit female dominance over males. Maternal investment in this species is enormous when compared with that seen in most carnivores (Hofer and East, 1995, 1993; Holekamp et al., 1996; Watts et al., 2009). In light of the highly specialized bone-cracking morphology in these animals, their prolonged period of offspring dependence, the protracted development of their skulls, and the intensive feeding competition characteristic of this species, we have hypothesized that constrained development of the feeding apparatus among juveniles, occurring in an environment characterized by intensive feeding competition, may have shaped the evolution of female dominance (Watts et al., 2009). Extant Crocuta evolved only 200,000990,000 years ago from ancestors specialized for scavenging and durophagy (Lewis and Werdelin, 2000). Trade-offs associated with development of a craniodental morphology competent for durophagy may have generated strong selection pressures during Crocuta's recent evolutionary shift to feeding in large groups on live prey, favoring not only rapid development of the morphological tools needed to cope with difficult foods but also favoring large, aggressive mothers able to help their cubs during competitive feeding (Watts et al., 2009). Although none of the other species included in Table 3 experience intensive feeding competition, evidence of delayed maturation in Crocuta relative to that in carnivores that do experience intense feeding competition on a regular basis would suggest that aggressiveness and social dominance have been favored in female spotted hyenas to help their offspring compensate for their poorlydeveloped feeding abilities long after weaning. To be able to crack open large bones with their jaws in adulthood, it appears the price paid by spotted hyenas has been delayed achievement of feeding performance maxima until long after weaning and puberty.

\section{ACKNOWLEDGMENTS}

We are grateful to the Kenyan Ministry of Education, Science, and Technology, Office of the President; the Narok County Council; the Senior Warden of the Masai Mara National Reserve; the National Museums of Kenya; and the Kenyan Wildlife Service for their permission to collect the specimens used here, and for their cooperation and support. We also are indebted to Don Swiderski, Terri McElhinny, Melissa Gallego, Laura Abraczinskas, and Paula Hildebrandt for their help on this project. We also thank three anonymous reviewers who provided valuable feedback and suggestions on a previous version of this manuscript. The methods used in this study are included in our Animal Research Protocol AUF 07/08-099-00, which was approved most recently on June 4, 2008 by the Institutional Animal Care and Use Committee at Michigan State University (MSU).

\section{LITERATURE CITED}

Alberch P, Gould SJ, Oster GF, Wake DB. 1979. Size and shape in ontogeny and phylogeny. Paleobiology 5:296-317.

Andresen PR, Bookstein FL, Conradsen K, Ersbøll B, Marsh J, Kreiborg S. 2000. Surface-bounded growth modeling applied 
to human mandibles. IEEE Trans Med Imaging 19:10531063.

Atkinson S. 1997. Reproductive biology of seals. Rev Reprod $2: 175-194$.

Bechshøft TØ, Sonne C, Rigét FF, Wiig Ø, Dietz R. 2008. Differences in growth, size and sexual dimorphism in skulls of East Greenland and Svalbard polar bears (Ursis maritimus). Polar Biol 31:945-958.

Bekoff M, Gese EM. 2003. Wild mammals of North America: Biology, management, and conservation. In: Feldhamer GA, Thompson BC, Chapman JA, editors. Coyote (Canis latrans). Baltimore, Maryland: John Hopkins University Press. pp 467-481.

Biknevicius AR. 1996. Functional discrimination in the masticatory apparatus of juvenile and adult cougars (Puma concolor) and spotted hyenas (Crocuta crocuta). Can J Zool 74:19341942.

Binder WJ. 1998. Functional Aspects of Tooth and Jaw Development in Large Carnivores, PhD Dissertation, University of California, Los Angeles.

Binder WJ, Van Valkenburgh B. 2000. Development of bite strength and feeding behaviour in juvenile spotted hyenas (Crocuta crocuta). J Zool 252:273-283.

Bookstein FL. 1996. Combining the tools of geometric morphometrics. In: Marcus LF, Corti M, Loy A, Naylor GJ, Slice DE, editors. Advances in Morphometrics. New York: Plenum Press. pp 131-151.

Bookstein FL. 1997. Landmark methods for forms without landmarks: Morphometrics of group differences in outline shape. Med Image Anal 1:97-118.

Bookstein FL, Streissguth AP, Sampson PD, Connor PD, Barr HM. 2002. Corpus callosum shape and neuropsychological deficits in adult males with heavy fetal alcohol exposure. Neuroimage 15:233-251.

Carrier, DR. 1996. Ontogenetic limits on locomotion performance. Physiol Zool 69:467-488.

Derocher AE, Stirling I. 1998. Maternal investment and factors affecting offspring size in polar bears (Ursus maritimus). J Zool Soc Lond 245:253-260.

Dessem, D, Druzinsky RE. 1992. Jaw-muscle activity in ferrets, Mustela putorious furo. J Morph 213:275-286.

Frank LG. 1986. Social organization of the spotted hyaena (Crocuta crocuta). I. Demography. Anim Behav 34:1500-1509.

Frank LG, Holekamp KE, Smale L. 1995. Dominance, demography, and reproductive success of female spotted hyenas. In: Sinclair ARE, Arcese P, editors. Serengeti II: Dynamics, Management, and Conservation of An Ecosystem. Chicago, Illinois: University of Chicago Press. pp 364-384.

Gaillard JM, Pontier D, Allainé D, Loison A, Herve JC, Heizmann A. 1997. Variation in growth form and precocity at birth in eutherian mammals. Proc R Soc Lond B 264:859868.

Gittleman JL. 1989. Carnivore Behavior, Ecology and Evolution. Ithaca, New York: Cornell University Press.

Gittleman JL, Van Valkenburgh B. 1997. Sexual dimorphism in the canines and skulls of carnivores: Effects of size, phylogeny, and behavioural ecology. J Zool 242:97-117.

Gould SJ. 1977. Ontogeny and Phylogeny. Harvard Univ. Press: Cambridge, Massachusetts.

Greaves WS. 1983. A functional analysis of carnassial biting. Biol J Linn Soc 20:353-363.

Greaves WS. 1985. The mammalian postorbital bar as a torsion-resisting helical strut. J Zool 207:125-136.

Green WDK. 1996. The thin-plate spline and images with curving features. In: Mardia,KV, Gill CA, Dryden IL, editors. Image Fusion and Shape Variability. Leeds: University of Leeds Press.pp 79-87.

Gunz P, Mitteroecker P, Bookstein FL. 2005. Semilandmarks in three dimensions. In: Slice DE, editor. Modern Morphometrics in Physical Anthropology. New York: Kluwer Academic/Plenum Publishers. pp 73-98.
Hattori K, Burdin AM, Suzuki M, Ohtaishi N. 2003. Age-related change and allometry of skull and canine of sea otters, Enhydra lutris. J Vet Med Sci 65:439-447.

Herrel A, Gibb AC. 2006. Ontogeny of performance in vertebrates. Physiol Biochem Zool 79:1-6.

Hildebrand M. 1984. Analysis of Vertebrate Structure. New York: Wiley.

Hofer H, East M. 1995. Population dynamics, population size, and the commuting system in Serengeti spotted hyenas. In: Sinclair ARE, Arcese P, editors. Serengeti II: Dynamics, Management, and Conservation of an Ecosystem. Chicago: University of Chicago Press. pp 332-363.

Hofer H, East ML. 1993. The commuting system of Serengeti spotted hyaenas: How a predator copes with migratory prey. III. Attendance and maternal care. Anim Behav 46:575-589.

Hofer H, East ML. 1996. The components of parental care and their fitness consequences: A life history perspective. Verh Dtsch Phys Ges Zool 89. 2:149-164.

Holekamp KE, Smale L. 1990. Provisioning and food sharing by lactating spotted hyenas. Crocuta crocuta (Mammalia: Hyaenidae). Ethology 86:191-202.

Holekamp KE, Smale L, Szykman M. 1996. Rank and reproduction in the female spotted hyaena. J Reprod Fertil 108:229237.

Hurov J, Henry-Ward W, Phillips L, German R. 1988. Growth allometry of craniomandibular muscles. tendons, and bones in the laboratory rat (Rattus norvegicus): relationships to oromotor maturation and biomechanics of feeding. Am $J$ Anat 182:381-394.

Koehl MAR. 1996. When does morphology matter? Ann Rev Ecol Syst 27:501-542.

Krkosek M, Lauzon-Guay J, Lewis MA. 2007. Relating dispersal and range expansion of California sea otters. Theor Popul Biol 71:401-407.

Kruuk H. 1972. The spotted hyena: a study of predation and social behavior. Chicago, Illinois: University of Chicago Press. p 335 .

Lewis ME, Werdelin L. 2000. The evolution of spotted hyenas (Crocuta). I U C N Hyaena Specialist Group Newsletter 7:3436.

Lombard LJ. 1971. Age determination and growth curves in the black-backed jackal. Canis mesomelas Schreber, 1775 (Carnivora: Canidae). Ann Transvaal Mus 27:135-181.

Mano T, Tsubota T. 2002. Reproductive characteristics of brown bears on the Oshima peninsula, Hokkaido, Japan. J Mamm 83:106-1034.

McKinney ML, McNamara KJ. 1991. Heterochrony: The Evolution of Ontogeny. Plenum Press: New York.

Mills MGL. 1990. Kalahari Hyaenas: Comparative Behavioral Ecology of Two Species. London: Unwin Hyman. p 303.

Mizuno AW, Ohtaishi N. 2002. Cranial features of the spotted seal. Phoca largha, in the Nemuro Strait, considering age effects. J Vet Med Sci 64:137-144.

Monteiro LR, Lessa LG, Abe AS. 1999. Ontogenetic variation in skull shape of Thrichomys apereoides (Rodentia: Echimyidae). J Mamm 80:102-111.

Ohdachi S, Aoi T, Mano T, Tsubota T. 1992. Growth, sexual dimorphism, and geographical variation of skull dimensions of the brown bear Ursus arctos in Hokkaido. J Mamm Soc Japan 17:27-47.

Radinsky LB. 1981. Evolution of skull shape in carnivores. I. Representative modern carnivores. Biol J Linn Soc 15:369388.

Rohlf FJ. 2005. tpsDig 2.10. NY: Stony Brook.

Rohlf FJ, Slice DE. 1990. Extensions of the Procrustes method for the optimal superimposition of landmarks. Syst Zool 39:40-59.

Sampson PD, Bookstein FL, Sheehan H, Bolson EL. 1996. Eigenshape analysis of left ventricular outlines from contrast ventriculograms. In: Marcus LF, Corti M, Loy A, Naylor GJP, Slice DE, editors. Advances in Morphometrics. New York: Nato ASI Series, Series A: Life Science. pp 131-152. 
Schweikher FP. 1930. Ectocranial suture closure in the hyaenas. Am J Anat 45:443-460.

Sheets DH. 2003. IMP-Integrated Morphometrics Package. Buffalo, NY: Department of Physics, Canisius College.

Smith KK. 1993. The form of the feeding apparatus in terrestrial vertebrates: Studies of adaptation and constraint. In: Hanken J, Hall BK, editors. The Skull. Chicago: University of Chicago Press. pp 150-185.

Tanner JB. 2007. Behavioral and morphological development in a female-dominated species, the spotted hyena (Crocuta croctuta), $\mathrm{PhD}$ Dissertation, Michigan State University, East Lansing, MI.

Tanner JB, Dumont ER, Sakai ST, Lundrigan BL, Holekamp KE. 2008. Of Arcs and Vaults: The Biomechanics of Bonecracking in the Spotted Hyena (Crocuta crocuta). Biol J Linn Soc 95:246-265.

Thomason JJ. 1991. Cranial strength in relation to estimated biting forces in some mammals. Can J Zool 69:2326-2333.

Thompson EN, Biknevicius AR, German R. 2003. Ontogeny of feeding function in the gray short-tailed opossum Monodelphis domestica: empirical support for the constrained model of jaw biomechanics. J Exp Bio 206:923-932.

Tinker MT, Doak DF, Estes JA, Hatfield BB, Staedler MM, Bodkin JL. 2006. Incorporation of diverse data and realistic complexity into demographic estimation procedures for sea otters. Ecol App 16:2293-2312.

Van Horn RC, McElhinney TL, Holekamp KE. 2003. Age estimation and dispersal in the spotted hyena (Crocuta crocuta). J Mamm 84:1019-1030.

Van Valkenburgh B. 1988. Incidence of tooth breakage among large, predatory mammals. Am Nat 131:291-302.
Van Valkenburgh B. 2007. Deja vu: The evolution of feeding morphologies in the Carnivora. Integr Comp Biol 47:147-163.

Wagner AP. 2006. Behavioral ecology of the striped hyaena (Hyaena hyaena), PhD Dissertation, Montana State University, Bozeman.

Wainwright PC. 1994. Functional morphology as a tool in ecological research. In: Wainwright PC, Reilly SM, editors. Ecological Morphology. Chicago: University of Chicago Press. pp 42-59.

Wainwright PC, Reilly SM, editors. 1994. Ecological Morphology. Chicago: University of Chicago Press.

Walton LR, Joly DO. 2003. Canis mesomelas. Mammalian Species. Am Soc Mamm 715:1-9.

Watts HE. 2007. Social and ecological influences on survival and reproduction in the spotted hyena, Crocuta crocuta, $\mathrm{PhD}$ Dissertation, Michigan State University, East Lansing, MI.

Watts HE, Tanner JB, Lundrigan BL, Holekamp KE. 2009. Postweaning maternal effects and the evolution of female dominance in the spotted hyena. Proc R Soc Lond B 276:2291-2298.

Werdelin L. 1989. Constraint and adaptation in the bone-cracking canid Osteoborus (Mammalia: Canidae). Paleobiology 15:387-401.

Zedrosser A, Støen O, Saebø S, Swenson JE. 2007. Should I stay or should I go? Natal dispersal in the brown bear. Anim Behav 74:369-376.

Zelditch ML, Lundrigan BL, Sheets HD, Garland T Jr. 2003. Do precocial mammals develop at a faster rate? A comparison of rates of skull development in Sigmodon fulviventer and Mus musculus domesticus. J Evol Biol 16:708-720.

Zelditch ML, Lundrigan BL, Garland T Jr. 2004. Developmental regulation of skull morphology. I. Ontogenetic dynamics of variance. Evol Dev 6:194-206. 